This is the post print version of the article, which has been published in

Folia Microbiologica. 2018, 63(2), 237-248. http://dx.doi.org/10.1007/s12223-017-0562-3.

This document has been downloaded from TamPub uta.fi

\title{
Changes in the Lung Bacteriome in Relation to Anti-pseudomonal Therapy in Children with Cystic
}

\section{Fibrosis}

Running title: Anti-pseudomonal Antibiotics and Lung Bacteriome in Cystic Fibrosis

Lenka Kramná ${ }^{1}$, Pavel Dřevínek ${ }^{2}, J_{a k e}$ Lin $^{3}$, Michal Kulich $^{4}$, Ondrej Cinek ${ }^{1}$

1) Department of Paediatrics, $2^{\text {nd }}$ Faculty of Medicine, Charles University in Prague and University Hospital Motol, Prague, Czech Republic

2) Department of Medical Microbiology, $2^{\text {nd }}$ Faculty of Medicine Charles University in Prague and University Hospital Motol, Prague, Czech Republic

3) University of Tampere, BioMediTech, Computational Biology, Tampere, Finland

4) Department of Probability and Mathematical Statistics, Faculty of Mathematics and Physics, Charles University, Prague, Czech Republic

\section{Correspondence to:}

Ondřej Cinek

Department of Paediatrics, University Hospital Motol

V Úvalu 84, Prague 5, CZ-15006, The Czech Republic

Ondrej.Cinek@Lfmotol.cuni.cz; phone +420 22443 2026; fax +420 224432020 


\section{Abstract}

The lung in cystic fibrosis (CF) is home to numerous pathogens that shorten the lives of patients. The aim of the present study was to assess changes in the lung bacteriome following antibiotic therapy targeting Pseudomonas aeruginosa in children with CF. The study included nine children (9-18 years) with CF who were treated for their chronic or intermittent positivity for Pseudomonas aeruginosa. The bacteriomes were determined in 16 pairs of sputa collected at the beginning and at the end of a course of intravenous antibiotic therapy via deep sequencing of the variable region 4 of the $16 \mathrm{~S}$ rRNA gene, and the total bacterial load and selected specific pathogens were assessed using quantitative real-time PCR. The effect of anti-pseudomonal antibiotics was observable as a profound decrease in the total 16S rDNA load $(\mathrm{p}=0.001)$ as well as in a broad range of individual taxa including Staphylococcus aureus $(\mathrm{p}=0.03)$ and several members of the Streptococcus mitis group (S.oralis, S. mitis, and S. infantis) $(\mathrm{p}=0.003)$. Improvements in forced expiratory volume $\left(\mathrm{FEV}_{1}\right)$ were associated with an increase in Granulicatella sp. $(\mathrm{p}=0.004)$, whereas a negative association was noted between the total bacterial load and white blood cell count $(\mathrm{p}=0.007)$. In conclusion, the data show how microbial communities differ in reaction to antipseudomonal treatment, suggesting that certain rare species may be associated with clinical parameters. Our work also demonstrates the utility of absolute quantification of bacterial load in addition to the $16 \mathrm{~S}$ rDNA profiling.

Key words: lung bacteriome; antibiotic therapy; cystic fibrosis; Pseudomonas aeruginosa; clinical parameters; children 


\section{Introduction}

Cystic fibrosis (CF) is caused by mutations in the gene for Cystic Fibrosis Transmembrane Conductase Regulator (CFTR) protein which, among other effects, causes impairments in mucociliary clearance. This enables bacteria to become established in the lungs, which leads to a decline in pulmonary function and ultimately to respiratory failure. One of the most important CF pathogens is Pseudomonas aeruginosa. This species often dominates the CF lung bacteriome not only in adults (Cox et al. 2010; Hauser et al. 2011) but also in a considerable number of children (Hauser et al. 2011; Li et al. 2005; Pillarisetti et al. 2011). Once present in the lower airways, it can cause chronic infections that are difficult to treat (Doring and Hoiby 2004). However, antibiotic treatment of patients with chronic $P$. aeruginosa infection occasionally improves the patient's health status, including their lung function, despite the fact that the quantity of the pathogen in the lower airways remains seemingly unchanged (Price et al. 2013; Zemanick et al. 2013). Pulmonary exacerbations in CF patients are not solely dependent on the presence of $P$. aeruginosa in the lung (Zemanick et al. 2010). Therefore, interest has expanded towards other species that may cohabit the lower airways and play either beneficial or harmful roles in the development of the CF lung disease (Zemanick et al. 2011). This area is especially important with respect to the lung bacteriome during childhood, which is believed to be amenable to changes (Coburn et al. 2015; Li et al. 2005).

Our study aimed to investigate changes in the lung bacteriome in patients with chronic or intermittent $P$. aeruginosa infection in relation to intravenous antibiotic treatment. The novel aspect of the study design was a combination of $16 \mathrm{~S}$ rDNA profiling with a set of species-specific PCR reactions that allowed us to measure changes in the absolute quantity of several bacterial species other than $P$. aeruginosa. 


\section{Material and Methods}

\section{Subjects}

All study subjects attended the CF Centre at the Motol University Hospital, Prague, the Czech Republic; this centre takes care of more than 200 children and young persons with the disease. The main inclusion criterion for the patients was an intermittent or chronic infection by $P$. aeruginosa (intermittent infections were characterized by less than $50 \%$ positive samples for $P$. aeruginosa over the last 12 months, while chronic infections were defined with more than $50 \%$ of samples for P. aeruginosa over the last 12 months, as per Leeds criteria (Lee et al. 2003)).

We recruited nine patients ( 7 females) aged from 9 to 18 years (median age 14.5 years); two of them (1 female) having intermittent $P$. aeruginosa infection and the remaining seven having chronic infection. The patients had a combined total of 16 courses of antibiotic therapy with a combination of intravenous antibiotics. Seven of the courses were indicated for pulmonary exacerbation, while nine were prescribed as part of chronic suppressive anti-pseudomonal therapy. Virtually every patient received a different cocktail of two or more antibiotics with the aim to control their P. aeruginosa infection. The choice of antibiotics (Supplementary Table S1) was based not only on susceptibility test results of the most recent $P$. aeruginosa isolate (Supplementary Table S2, supplementary material S1.1) but also on drug toxicity, tolerability and clinical benefit observed upon their previous use (Doring et al. 2012). Patient records of inflammatory markers [white blood cell (WBC) count, C-reactive protein (CRP)] and forced expiratory volume $\left(\mathrm{FEV}_{1}\right)$ were also collected (Table S1). The study was run between September 2012 and November 2013. A written consent was obtained from all patients or their guardians, and the study was approved by the institutional Ethics Committee, University Hospital Motol, Prague on September 19, 2012, EK-1445/12. 


\section{Sputum samples}

Spontaneously expectorated sputum was collected on the day when antibiotic therapy started and on the last day of antibiotic treatment, hereinafter referred to as "before" and "after" antibiotic therapy. The courses of antibiotic therapy lasted from 11 to 21 days (median 13.5 days). Three patients provided a single pair of samples covering one course of antibiotic therapy, five patients underwent two courses, and one patient had three courses of the therapy. The time interval between multiple applications of intravenous antibiotics ranged from 79 to 212 days (median 120 days). We analysed a total of 32 samples, and they were also investigated by routine culture-based microbiological methods and microscopically validated as lower airways samples.

\section{DNA extraction}

An aliquot of sputum was frozen immediately upon expectoration. When thawed, it was liquefied with a mixture of saline with $46 \mathrm{mmol} / \mathrm{L} \mathrm{KH}_{2} \mathrm{PO}_{4}, 32 \mathrm{mmol} / \mathrm{L} \mathrm{NaOH}$ and $0.9 \mathrm{mg} / \mathrm{mL}$ acetylcysteine (Hexal AG, Holzkirchen, Germany) and centrifuged. The bacterial pellet was pre-treated by incubation with $50 \mu \mathrm{g}$ lysostaphin (Sigma-Aldrich, St. Louis, MO, USA) for $1 \mathrm{~h}$ at $37^{\circ} \mathrm{C}$, followed by incubation with proteinase K; DNA was then extracted using a QIAamp DNA kit (Qiagen, Hilden, Germany). The extraction efficiency was checked by adding a plasmid containing a fragment of Arabidopsis thaliana DNA as an exogenous internal control that was then quantified using a specific PCR reaction; this control was not intended for normalizing for the sputum content.

\section{Deep sequencing profiling of the $16 S$ rDNA and data processing}

Deep sequencing to identify the content and structure of bacterial community targeted the V4 region of the 16S rRNA gene and was performed on a MiSeq sequencer with a 2x250 bp sequencing kit (Illumina, San Diego, CA, USA). Data were processed using the tools QIIME (Caporaso et al. 2010) and Mothur (Schloss et al. 2009). The process is described in detail in supplementary material, S2.1 and S2.2. To 
control the sequencing process and subsequent analysis steps, an artificial Mock Community was sequenced along with the samples (courtesy of BEI Resources, NIAID, NIH; Genomic DNA from Microbial Mock Community B - Even, Low Concentration - v5.1L, for 16S rRNA Gene Sequencing, HM-782D). All samples including the Mock Community and negative controls were sequenced in triplicate, with each replicate prepared in a separate PCR plate.

Conversion of data from $16 S$ rDNA relative quantity to absolute quantities and specific PCR

To estimate the absolute quantities of individual taxonomic units per $\mu$ L DNA, we used the quantification results of the overall 16S rDNA content (supplementary material S2.3). To validate the above estimations of absolute quantity, we checked the following pathogens by specific quantitative PCR in real-time format: Pseudomonas aeruginosa, Staphylococcus aureus, Haemophilus influenzae and three members of the Streptococcus mitis group (reaction detecting S. oralis, S. mitis, and S. infantis) (supplementary material S2.4).

The clinical and sequencing data as well as generic and specific PCR results have been deposited at the NCBI Sequence Read Archive (SRA) under project ID PRJNA339813; the study ID for the sample data is SRP083112.

\section{Diversity metrics, markers of inflammation and statistical analysis}

Alpha diversity was measured based on an OTU table normalized for 10,000 reads per sample by several indices (Observed species, Chao1, ACE, Shannon, Simpson, Inverse Simpson and Fisher; paired t-test).

For analyses based on relative quantity, operational taxonomic units (OTUs) were clustered based on 97\% similarity and filtered for being present in at least $5 \%$ of samples by at least 50 reads. The dominant 
pathogen in each sample was defined as the one exceeding by at least two times the relative abundance of the second most abundant taxon (Carmody et al. 2013; Coburn et al. 2015).

Species richness and evenness was compared using Shannon index between groups of samples from patients positive and negative for markers of inflammation: the upper normal limits were $13 \times 10^{9} / \mathrm{L}$ WBC and $8 \mathrm{mg} / \mathrm{L} \mathrm{CRP}$. The effect of antibiotic treatment on the total bacterial load and on absolute concentrations of abundant taxa was assessed using the Wilcoxon paired test with the Bonferroni adjustment for multiple comparisons, and the associations with clinical outcomes ( $\mathrm{FEV}_{1} \%$ predicted, WBC count, CRP) were assessed using generalized estimating equations in models which accounted for the repeated character of measurements. Analyses were performed using R package version 3.2.2 (R Core Team 2016) and the phyloseq package (McMurdie and Holmes 2013). 


\section{Results}

To analyse both the overall bacteriome composition and the quantity of its most abundant individual species, we exploited features of two different molecular approaches. While the taxa identification with their relative abundance was obtained by the $16 \mathrm{~S}$ rDNA profiling using next generation sequencing (NGS), the absolute quantity of selected taxa was determined by using either a species-specific RQ-PCR [P. aeruginosa, S. aureus, $H$. influenzae and part of the Streptococcus mitis group (S. oralis, S. mitis, $S$. infantis)], or for less traditional CF-related pathogens, a product of relative abundance from 16S rDNA profiling with quantity from $16 \mathrm{~S}$ rDNA panbacterial RQ-PCR. The results obtained by both approaches are summarized in Figure 1 A - D.

Bacterial taxa change upon antibiotic therapy in both absolute and relative quantities The 16S rDNA triplicates of each sample were inspected for consistency using clustering graphs and merged, yielding between 48,641 and 194,050 sequences per sample (interquartile range 25,179 - 38,663; median 29,206). The total number of 824 OTUs were generated, many of them belonging to well-known CF pathogens, such as Pseudomonas aeruginosa, Staphylococcus aureus, Haemophilus influenzae, Stenotrophomonas maltophilia and Achromobacter xylosoxidans. The first 11 taxa ranked by overall relative abundance are listed in Table 1, where their quantities are compared before and after the therapy. S. aureus was the most abundant pathogen in our samples, followed by $P$. aeruginosa. The effect of antipseudomonal antibiotics on the relative 16S rDNA profiles as well as on absolute quantities was significant yet heterogeneous among individual taxa (Figures 2, Supplemental Figure S1, Figure 2). We noted a substantial decrease in the total bacterial load following antibiotic therapy $(p=0.001$, Figure 1C); this decrease was most profound in the samples where $S$. aureus or P. aeruginosa dominated.

The absolute quantity of $S$. aureus measured by species-specific PCR showed a constant and significant decrease $\left(\right.$ Figure 2, $\left.\mathrm{P}_{\text {corrected }}=0.03\right)$ and responded well to anti-pseudomonal treatment with post- 
antibiotic quantities that were often undetectable. The 16S rDNA profiling showed that $S$. aureus was dominant in pre-antibiotic samples from five courses of antibiotic therapy but remained the most abundant only in two of them following antibiotic therapy (Figure 2A), again indicating a profound response to antibiotic treatment. However, in two post-antibiotic samples ( $\mathrm{P} 4$ course 2, $\mathrm{P} 8$ course 2), 16S rDNA profiling showed an increase in relative abundance of Staphylococcus spp. (comprising S. aureus, S. epidermidis, and S. hominis), while species-specific PCR targeting only S. aureus was negative (Figure 2A). This implies that S. epidermidis and/or S. hominis were responsible for this increase, as the V4 region of the 16S rRNA gene is identical for the three species, and they cannot be distinguished by the NGS method alone.

$P$. aeruginosa was ranked second in quantity after $S$. aureus and was detected in 8 courses of antibiotic therapy by NGS and in 11 courses by species-specific PCR (Figure 2B). P. aeruginosa dominated the lung bacteriome in three of eight pseudomonas-positive pre-antibiotic samples and in three of seven postantibiotic samples (Table 1). P. aeruginosa was susceptible to antibiotics with a decrease in its absolute quantity in most cases (7 of 11 courses, Figure 2B). However, overall changes in $P$. aeruginosa quantity seemed to be dependent on its proportion in the bacteriome: two courses of antibiotic therapy (P7 course 2, P9 course 1) in patients, whose samples were not dominated by P. aeruginosa, resulted in almost no change in its absolute quantity after antibiotic treatment. Furthermore, in two courses (P2 course 2, P6 course 1) both the absolute and relative quantities of $P$. aeruginosa significantly increased despite the fact that in-vitro antibiotic susceptibility tests showed that it was susceptible to the antibiotics used (Table S2). In both cases P. aeruginosa was not a dominant species in the pre-antibiotic sample.

In addition to $P$. aeruginosa and $S$. aureus, other traditional CF pathogens were also found in the preantibiotic samples. H. influenzae and A. xylosoxidans were both dominant in the pre-antibiotic samples (Figure 2, Figure S1 C), and both responded well to anti-pseudomonal treatment ( $\mathrm{P}_{\text {corrected }}$ for $H$. 
influenzae $=0.055)$. By contrast, $S$. maltophilia was dominant only after antibiotic therapy and the increase with therapy was observed also in absolute numbers(Figure 1B). Several members of the Streptococcus mitis group (S. oralis, S. mitis, and S. infantis) detected by group-specific real-time PCR also showed a significant and consistent absolute decrease with antibiotic treatment $\left(\mathrm{P}_{\text {corrected }}=0.003\right)$

\section{(Figure S1 D).}

\section{Exploration of alpha diversity}

Antibiotic therapy for pulmonary exacerbations was borderline-associated with a decrease in the complexity of the lung bacteriome (Supplementary Figure S2). This tendency towards the decrease in diversity was indicated by some alpha (within-sample) diversity indices (Observed species, $\mathrm{p}_{\mathrm{raw}}=0.03$, Chao1, $\mathrm{p}_{\text {raw }}=0.05$, and ACE, $\mathrm{p}_{\text {raw }}=0.03$, Fisher, $\mathrm{p}_{\text {raw }}=0.022 ;$ paired t-test $)$, but in contrast, the Shannon and Simpson diversity indices, often used for their ability to also distinguish the evenness of the species distribution, did not appreciably change ( $\mathrm{p}_{\mathrm{raw}}=0.89, \mathrm{p}_{\mathrm{raw}}=0.74$, respectively).

\section{Association with clinical markers, and with the dominant pathogens}

Species richness measured by Shannon index had a borderline-significant tendency towards inverse association with CRP, but not with increased leukocytes (Supplemental Figure S2 - B). A significantly lower Shannon index was found in samples with dominant pathogens among the 'traditional' CF-related bacteria (P. aeruginosa, S. aureus, A. xylosoxidans, H. influenzae, S. maltophilia), $\mathrm{P}<10^{-5}$ when compared to samples without a dominant species, or with samples dominated by other organisms. The Shannon index also decreased with decreasing values of FEV1\%, p = 0.003 (Supplemental Figure S2 B).

We then tested the association of the 11 most abundant taxa (Table 1) with a change in markers of clinical improvement. The 11 taxa were chosen based on their presence as a dominant pathogen or based 
on their average relative abundance in all samples higher than 5\%. The following clinical parameters were tested: $\mathrm{FEV}_{1} \%$ predicted, as a parameter of lung function, and WBC count and CRP, as markers of inflammation. An association with improvement of lung function was found for Granulicatella sp. (present in five pre-antibiotic samples and six post-antibiotic samples); in the regression model, a ten-fold increase in its quantity was associated with an increase in the $\mathrm{FEV}_{1}$ of $5.5 \%(\mathrm{p}=0.004)$. We also detected a significant association of the total bacterial load with the WBC count; a ten-fold decrease in the total $16 \mathrm{~S}$ rDNA load was associated with a decrease in WBCs by $2 \times 10^{9} / \mathrm{L}(\mathrm{p}=0.007)$. No associations with CRP levels were noted.

\section{Correlation between specific PCR detection and $16 S$ rDNA profiling}

To assess the accuracy of calculated absolute quantities (obtained by the conversion of the taxon proportion from the NGS $16 \mathrm{~S}$ rDNA profile, multiplied by the total 16S rDNA load from generic realtime PCR), these values were directly compared to quantities from species-specific real-time PCR. The comparison for P. aeruginosa is illustrated in Supplementary Figure S6. Although the overall results acceptably correlate $\left(\mathrm{R}=0.92, \mathrm{p}<10^{-10}\right.$; Spearman rank correlation test), a discrepancy can be noted in samples found negative by specific PCR: here the 16S rDNA NGS profiling reports a low, but positive signal. Similarly to P. aeruginosa, in S. aureus and H. influenzae the absolute quantities obtained by PCR and NGS correlate generally well ( $\mathrm{p}<10^{-6}$, Spearman rank correlation test), but NGS yielded several false-positive samples.

\section{Relative and absolute quantification}

Presented results were obtained by using two different approaches, the relative quantity resulting from $16 \mathrm{~S}$ sequencing and absolute quantity obtained by either species-specific PCR or by a conversion of $16 \mathrm{~S}$ results with the total $16 \mathrm{~S}$ load. Inspecting the same pairs of sputum samples, the results by both approaches differed, as illustrated in Figure 2: in 2 antibiotic courses species-specific PCR reported a 
decrease in quantity of $P$. aeruginosa while an increase in relative quantity was reported by $16 \mathrm{~S}$ sequencing(courses P2c1, P9c1). Similar inconsistency was noted for S. aureus (course P9c1, courses $\mathrm{P} 4 \mathrm{c} 2$ and $\mathrm{P} 8 \mathrm{c} 2$ reported an increase of relative abundance of $S$. epidermidis/hominis) and for other species (data not shown).

\section{Contaminating signals}

The analysis of multiple negative controls indicated that the signal of E. coli most likely originated from PCR chemicals rather than from the sputum itself (Supplementary Figure S3). The signal of Escherichia coli, which was found in all samples in average proportion of $2.4 \%$, also seemed to change with the antibiotic therapy: it consistently increased in relative quantity in all post-antibiotic sputum samples (Supplementary Figures S4 - A, S5). After a conversion of E.coli 16S profiles to absolute quantity values by multiplication with the total $16 \mathrm{~S}$ load, an actual decrease of quantity was noted in 9 courses of antibiotic therapy (Supplementary Figures S4 - B) and the change in E. coli absolute quantity seemed to inversely copy the change in absolute bacterial concentration (Supplementary Figure S5, S4C). 


\section{Discussion}

Our study assessed the lung bacteriome profiles in sputum samples from paediatric patients chronically or intermittently infected with $P$. aeruginosa. Samples were taken at the beginning and at the end of intravenous antibiotic treatment either as a part of maintenance treatment or for treating an acute exacerbation. Both the total bacterial load and the composition of the sputum 16S rDNA profile changed in all sputum pairs. Apart from detection of changes in the bacteriome we also compared different methods used for studying lung microbes.

The total bacterial load, measured by quantitative real-time PCR of the $16 \mathrm{~S}$ rDNA, significantly decreased following antibiotic therapy; this decrease was as great as four orders of magnitude over two weeks and was significantly associated with a decrease in WBCs. However, the total bacterial load change was not associated with changes in lung function $\left(\mathrm{FEV}_{1} \%\right)$, which can be explained by the degree of diversity among individual lung microbiota that contained species ranging from obligate CF pathogens to bacteria potentially beneficial to $\mathrm{CF}$ patients. The rapid and profound response of the total bacterial load to the i.v. therapy may indicate plasticity of paediatric lung bacteriome; this observation is in contrast to data published in adults (Price et al. 2013; Zemanick et al. 2013).

Diversity indices enabled us to observe the complexity of the bacteriome. The most important driver of alpha (within-sample) diversity was the dominant pathogen, as has been reported by previous studies (Carmody et al. 2015; Coburn et al. 2015; Filkins et al. 2012). Communities dominated by streptococci were associated with significantly higher diversity than those dominated by Pseudomonas or Staphylococcus. Furthermore, Streptococcus-driven communities are also known to be very stable not only during periods of clinical stability but also during periods of exacerbation (Carmody et al. 2015), which was true e.g. for all three courses of antibiotic therapy experienced by patient 5 (Figure 2). 
Interestingly, higher species richness was associated with better clinical status, as measured by FEV1 and marginally also by CRP as a marker of inflammation. Similar association was observed in other studies (Coburn et al. 2015; Fodor et al. 2012; van der Gast et al. 2014; Zhao et al. 2012).We believe that the richer species distribution in such communities (which are devoid of classical CF pathogens) can better mimic the transient polymicrobial nature of healthy lungs and can be a marker of less severe lung disease in CF patients, as previously described (Zhao et al. 2012). Alpha diversity indices of Observed species, Chao1 and ACE significantly decreased with therapy, whereas the Shannon and Simpson indices did not. The latter two represent richness as well as evenness, and their usage has been encouraged by other studies (Carmody et al. 2015; Carmody et al. 2013; Price et al. 2013; Zemanick et al. 2013).

A considerable response to anti-pseudomonal therapy was noted for all detected CF-related pathogens, such as P. aeruginosa, S. aureus, H. influenzae, and A. xylosoxidans, confirming that anti-pseudomonal treatment was effective against a broad spectrum of pathogens. In two instances (courses P2c2 and P6c1), other pathogens (H. influenzae, S. aureus) were profoundly reduced, whereas P. aeruginosa increased both in relative proportion and absolute numbers despite its in vitro sensitivity to the administered antibiotics. The reason for this is not at hand - heterogeneity of $P$. aeruginosa strains which co-exist in the lungs probably plays a role (Winstanley et al. 2016). A similar relative increase of the bacterium during antipseudomonal therapy was reported by Daniels et al. (Daniels et al. 2013) using a T-RFLP method; however, the authors reported no absolute bacterial quantities; therefore, their results are difficult to compare to the present observations.

Apart from these commonly detected pathogens, we observed a number of species that are less often regarded to be part of traditional CF microbiology, especially anaerobes. These species are becoming a focus of research for their relatively frequent occurrence as dominant pathogens (Carmody et al. 2015; Price et al. 2013) even at the time of pulmonary exacerbations (Zemanick et al. 2010) when the 16S 
rDNA profiling of CF respiratory samples is applied. Proving causative links has been extremely complicated because of their concurrent occurrence in the upper airways (Goddard et al. 2012) and the lack of routine culture-based results. Interestingly, the species-specific PCR showed that several members of the Streptococcus mitis group (S. oralis, S. mitis, and S. infantis) significantly decreased in quantity upon antibiotic therapy. Streptococci found in the sputum samples have also been often identified in oral flora (Filkins et al. 2012), which complicates our understanding their role in CF lungs, as they might originate from upper airways. This effect is especially true for children because of their limited ability to expectorate sputum. However, many studies support the presence of streptococci and other non CFrelated species in lower airways and their potential role in CF lung disease, as reviewed by Caverly et al. (Caverly et al. 2015).

At present, we have no plausible explanation for the positive association of Granulicatella spp. with increased $\mathrm{FEV}_{1}$. The genus Granulicatella was established in 2000 and previously belonged to nutritionally variant streptococci (Cargill et al. 2012). The genus is a component of the normal oral microflora, similar to the viridans streptococci that were also found in CF lungs (Cargill et al. 2012; Filkins et al. 2012). The genetic relatedness of Granulicatella to these streptococci can also be indicative of its association with better lung function, similar to what was observed for streptococci (Filkins et al. 2012). To the best of our knowledge, no association between clinical status and Granulicatella has been described, so the finding merits further investigation. Indeed, relationships similar to what we detected, especially for non-CF related pathogens, are known from the literature, but no consistent conclusions can be drawn (Carmody et al. 2013; Zemanick et al. 2013). Interestingly, Granulicatella adiacens was found to be associated with the lung cancer (Cameron et al. 2017), which may further support its utility as a marker organism in various processes. 
One strength of our study is the focus on children, an age group often underrepresented in the literature regarding the lung bacteriome. Similar to other authors, we believe that bacteriome features are different in children compared to adult patients. A study by van der Gast et al. (van der Gast et al. 2014) that included children and adults with different chronic lung diseases revealed a high degree of clustering within the paediatric cohorts; however, the adults clustered neither within the adult cohort nor with their paediatric counterparts. Interestingly, the most common species detected in paediatric patient cohorts were also found in four healthy children included in that study. Children and adults are also reported to differ with regard to species richness; higher species richness is associated with better lung function in children (Coburn et al. 2015; van der Gast et al. 2014). Antibiotic treatment for pulmonary exacerbation represents the key factor for species turnover, as described previously (Cuthbertson et al. 2015), and is therefore an important variable in shaping the lung bacteriome.

A second strength of our study is that we determined both relative and absolute quantities of bacterial species. 16S rDNA profiling, which confers the information about relative quantity only, was utilized for identification of taxa and to determine their fraction in the bacteriome. However, the real effect of antibiotics on bacterial mass cannot be revealed unless absolute quantities are also known. The situation is exemplified in Figure 1, where an increase of relative proportion of bacteria was noted while the "true", absolute quantity reported a decrease in several instances. Although most studies describe bacterial lung communities by relative abundance (Coburn et al. 2015; Cuthbertson et al. 2015; van der Gast et al. 2014), few have also evaluated the absolute quantity (Carmody et al. 2015; Zemanick et al. 2013). We used specific real-time PCR to quantify not only the overall bacterial load but also the four most important groups of CF pathogens. The use of absolute quantities also helps resolve the weak contamination of PCR polymerases by bacterial DNA. It is known that some recombinant polymerases are weakly contaminated by E. coli $16 \mathrm{~S}$ rDNA or other bacterial DNA (Spangler et al. 2009). This 
contamination emerges in the bacteriome profiles only if there is little bacterial DNA in the sample; the contaminant proportion, therefore, logically increases in post-antibiotic samples (Figure S4).

The use of two methodological approaches also revealed the difference in the true detection thresholds and specificity: species-specific PCR performed better than NGS 16S profiling. The NGS profiling produces several false low-positive signal, probably caused by a signal cross-bleed among samples. This is a known phenomenon caused by imperfection in the currently available sample indexing strategy, and has been reported by others and us (Kircher et al. 2012; Kramna et al. 2015). Furthermore, low abundance bacteria may be diminished in the $16 \mathrm{~S}$ profiles - more abundant species are amplified preferentially as compared to species present in low quantities (Gonzalez et al. 2012).

Among the limitations, we do not know whether we detected predominantly live bacteria, or also leftovers of DNA from dead cells. Detecting DNA from dead bacterial cells may lead to underestimation of the antibiotic effect on taxa, as reported by Rogers et al. (Rogers et al. 2010). Given that the dynamics of bacteriome profile changes were extreme (several orders of magnitude quantity changes), we believe that the majority of the signal came from live organisms. Secondly, the use of chemicals such as propidium monoazide (PMA) enables one to block the dead cell signal; however, numerous other issues connected with the use of PMA may act as a source of bias, as reviewed in (Caverly et al. 2015). The quantitative PCR efficacy may also marginally differ among species, as the bacteria do not have equal copy numbers of the 16S rRNA genes, and primers themselves may also vary in efficacy; the assessment of calibration curves, however, suggested that this source of variation is not prominent. Furthermore, we used lysostaphin, but no other enzymes in the DNA extraction protocol. Rather than sole use of lysostaphin, it seems that the present protocols tend towards enzyme cocktails, although their composition has not been agreed upon universally (Bera et al. 2005). A cocktail of enzymes might have further improved the lysis of bacterial walls (Bag et al. 2016; Yuan et al. 2012). 
Furthermore, the use of the sole V4 region was not be able to distinguish among certain groups of pathogens, such as for staphylococci: S. aureus, S. epidermidis, S. hominis. While S. aureus is known pathogen, other two have been reported as comensals on the skin (Otto 2009; Weinstein et al. 1998) and have not normally been linked with a lung condition. Most of the time they appear as sample contaminants (Otto 2009; Weinstein et al. 1998), so the presently available data cannot resolve whether the increase in their quantity observed in treatment courses P4c2 and P8c2 are genuine or not.

Finally, our data have limited generalizability, primarily because of the limited patient sample size, frequency of sampling and a gender imbalance. It was previously reported that females are more prone to a progression of pseudomonal infection than males (Chotirmall et al. 2012). We also did not take into account the fact that the virulence of individual taxa likely changes when crossing a certain quorum (Ulrich et al. 2010). At last, our results monitor only the period of antibiotic treatment and we do not know what happened later during the recovery, as studied elsewhere (Cuthbertson et al. 2015; Price et al. 2013).

In conclusion, our study exemplifies the heterogeneity of changes in the composition of the paediatric lung bacteriome following intravenous therapy for chronic or intermittent infection with P. aeruginosa. This study supports the use of absolute bacterial counts derived from the combination of total bacterial load quantification by real-time PCR and $16 \mathrm{~S}$ rDNA profiling using next generation sequencing. Finally, we observed a possible novel association of Granulicatella sp. with an improvement in lung function. 


\section{Acknowledgements:}

The authors wish to thank Drs. Klára Vilimovská-Dědečková, Veronika Skalicka, Jana Bartosova and Tereza Jenik. Further, we would like to thank M. Antuskova for technical assistance and A. Bilkova for help with clinical data collection.

The study was funded by the Grant Agency of Charles University in Prague, grant No. 400213.

Author contributions: L.K.: processed the samples, prepared the libraries, performed sequencing, analysed data, and wrote the manuscript; P.D.: conceived the study and helped in manuscript writing; J.L, M.K.: performed statistical analysis; OC: supervised the molecular analysis protocol, analysed data and helped in manuscript writing. 


\section{References:}

Bag S, Saha B, Mehta O, Anbumani D, Kumar N, Dayal M, Pant A, Kumar P, Saxena S, Allin KH, Hansen T, Arumugam M, Vestergaard H, Pedersen O, Pereira V et al. (2016) An Improved Method for High Quality Metagenomics DNA Extraction from Human and Environmental Samples. Sci Rep 6:26775. doi:10.1038/srep26775

Bera A, Herbert S, Jakob A, Vollmer W, Gotz F (2005) Why are pathogenic staphylococci so lysozyme resistant? The peptidoglycan O-acetyltransferase OatA is the major determinant for lysozyme resistance of Staphylococcus aureus. Mol Microbiol 55:778-787. doi:MMI4446 [pii]

10.1111/j.1365-2958.2004.04446.x

Cameron SJS, Lewis KE, Huws SA, Hegarty MJ, Lewis PD, Pachebat JA, Mur LAJ (2017) A pilot study using metagenomic sequencing of the sputum microbiome suggests potential bacterial biomarkers for lung cancer. PLoS One 12:e0177062. doi:10.1371/journal.pone.0177062

Caporaso JG, Kuczynski J, Stombaugh J, Bittinger K, Bushman FD, Costello EK, Fierer N, Pena AG, Goodrich JK, Gordon JI, Huttley GA, Kelley ST, Knights D, Koenig JE, Ley RE et al. (2010) QIIME allows analysis of high-throughput community sequencing data. Nat Methods 7:335-336.

Cargill JS, Scott KS, Gascoyne-Binzi D, Sandoe JA (2012) Granulicatella infection: diagnosis and management. J Med Microbiol 61:755-761. doi:10.1099/jmm.0.039693-0

Carmody LA, Zhao J, Kalikin LM, LeBar W, Simon RH, Venkataraman A, Schmidt TM, Abdo Z, Schloss PD, LiPuma JJ (2015) The daily dynamics of cystic fibrosis airway microbiota during clinical stability and at exacerbation. Microbiome 3:12. doi:10.1186/s40168-015-0074-9

Carmody LA, Zhao J, Schloss PD, Petrosino JF, Murray S, Young VB, Li JZ, LiPuma JJ (2013) Changes in cystic fibrosis airway microbiota at pulmonary exacerbation. Ann Am Thorac Soc 10:179-187. doi:10.1513/AnnalsATS.201211-107OC

Caverly LJ, Zhao J, LiPuma JJ (2015) Cystic fibrosis lung microbiome: opportunities to reconsider management of airway infection. Pediatr Pulmonol 50 Suppl 40:S31-38. doi:10.1002/ppul.23243

Coburn B, Wang PW, Diaz Caballero J, Clark ST, Brahma V, Donaldson S, Zhang Y, Surendra A, Gong Y, Elizabeth Tullis D, Yau YC, Waters VJ, Hwang DM, Guttman DS (2015) Lung microbiota across age and disease stage in cystic fibrosis. Sci Rep 5:10241. doi:10.1038/srep10241

Cox MJ, Allgaier M, Taylor B, Baek MS, Huang YJ, Daly RA, Karaoz U, Andersen GL, Brown R, Fujimura KE, Wu B, Tran D, Koff J, Kleinhenz ME, Nielson D et al. (2010) Airway microbiota and pathogen abundance in age-stratified cystic fibrosis patients. PLoS One 5:e11044. doi:10.1371/journal.pone.0011044

Cuthbertson L, Rogers GB, Walker AW, Oliver A, Green LE, Daniels TW, Carroll MP, Parkhill J, Bruce $\mathrm{KD}$, van der Gast CJ (2015) Respiratory microbiota resistance and resilience to pulmonary exacerbation and subsequent antimicrobial intervention. ISME J. doi:10.1038/ismej.2015.198

Daniels TW, Rogers GB, Stressmann FA, van der Gast CJ, Bruce KD, Jones GR, Connett GJ, Legg JP, Carroll MP (2013) Impact of antibiotic treatment for pulmonary exacerbations on bacterial diversity in cystic fibrosis. J Cyst Fibros 12:22-28. doi:10.1016/j.jcf.2012.05.008

Doring G, Flume P, Heijerman H, Elborn JS (2012) Treatment of lung infection in patients with cystic fibrosis: current and future strategies. J Cyst Fibros 11:461-479. doi:10.1016/j.jcf.2012.10.004

Doring G, Hoiby N (2004) Early intervention and prevention of lung disease in cystic fibrosis: a European consensus. J Cyst Fibros 3:67-91. doi:10.1016/j.jcf.2004.03.008

Filkins LM, Hampton TH, Gifford AH, Gross MJ, Hogan DA, Sogin ML, Morrison HG, Paster BJ, O'Toole GA (2012) Prevalence of streptococci and increased polymicrobial diversity associated with cystic fibrosis patient stability. J Bacteriol 194:4709-4717. doi:10.1128/JB.00566-12 
Fodor AA, Klem ER, Gilpin DF, Elborn JS, Boucher RC, Tunney MM, Wolfgang MC (2012) The adult cystic fibrosis airway microbiota is stable over time and infection type, and highly resilient to antibiotic treatment of exacerbations. PLoS One 7:e45001. doi:PONE-D-12-13611

Goddard AF, Staudinger BJ, Dowd SE, Joshi-Datar A, Wolcott RD, Aitken ML, Fligner CL, Singh PK (2012) Direct sampling of cystic fibrosis lungs indicates that DNA-based analyses of upperairway specimens can misrepresent lung microbiota. Proc Natl Acad Sci U S A 109:13769-13774. doi:10.1073/pnas.1107435109

Gonzalez JM, Portillo MC, Belda-Ferre P, Mira A (2012) Amplification by PCR Artificially Reduces the Proportion of the Rare Biosphere in Microbial Communities. PLoS One 7:e29973. doi:10.1371/journal.pone.0029973

Hauser AR, Jain M, Bar-Meir M, McColley SA (2011) Clinical Significance of Microbial Infection and Adaptation in Cystic Fibrosis. Clin Microbiol Rev 24:29-70. doi:10.1128/CMR.00036-10

Chotirmall SH, Smith SG, Gunaratnam C, Cosgrove S, Dimitrov BD, O'Neill SJ, Harvey BJ, Greene CM, McElvaney NG (2012) Effect of estrogen on pseudomonas mucoidy and exacerbations in cystic fibrosis. N Engl J Med 366:1978-1986. doi:10.1056/NEJMoa1106126

Kircher M, Sawyer S, Meyer M (2012) Double indexing overcomes inaccuracies in multiplex sequencing on the Illumina platform. Nucleic Acids Res 40:e3. doi:10.1093/nar/gkr771

Kramna L, Kolarova K, Oikarinen S, Pursiheimo JP, Ilonen J, Simell O, Knip M, Veijola R, Hyoty H, Cinek O (2015) Gut virome sequencing in children with early islet autoimmunity. Diabetes Care 38:930-933. doi:10.2337/dc14-2490

Lee TW, Brownlee KG, Conway SP, Denton M, Littlewood JM (2003) Evaluation of a new definition for chronic Pseudomonas aeruginosa infection in cystic fibrosis patients. J Cyst Fibros 2:29-34. doi:10.1016/S1569-1993(02)00141-8

Li Z, Kosorok MR, Farrell PM, Laxova A, West SE, Green CG, Collins J, Rock MJ, Splaingard ML (2005) Longitudinal development of mucoid Pseudomonas aeruginosa infection and lung disease progression in children with cystic fibrosis. JAMA 293:581-588. doi:10.1001/jama.293.5.581

McMurdie PJ, Holmes S (2013) phyloseq: an R package for reproducible interactive analysis and graphics of microbiome census data. PLoS One 8:e61217. doi:10.1371/journal.pone.0061217

Otto M (2009) Staphylococcus epidermidis--the 'accidental' pathogen. Nat Rev Microbiol 7:555-567. doi:10.1038/nrmicro2182

Pillarisetti N, Williamson E, Linnane B, Skoric B, Robertson CF, Robinson P, Massie J, Hall GL, Sly P, Stick S, Ranganathan S (2011) Infection, inflammation, and lung function decline in infants with cystic fibrosis. Am J Respir Crit Care Med 184:75-81. doi:10.1164/rccm.201011-1892OC

Price KE, Hampton TH, Gifford AH, Dolben EL, Hogan DA, Morrison HG, Sogin ML, O'Toole GA (2013) Unique microbial communities persist in individual cystic fibrosis patients throughout a clinical exacerbation. Microbiome 1:27. doi:10.1186/2049-2618-1-27

R Core Team (2016) R: A Language and Environment for Statistical Computing. R Foundation for Statistical Computing, Vienna, Austria, URL https://www.R-project.org/

Rogers GB, Marsh P, Stressmann AF, Allen CE, Daniels TV, Carroll MP, Bruce KD (2010) The exclusion of dead bacterial cells is essential for accurate molecular analysis of clinical samples. Clin Microbiol Infect 16:1656-1658. doi:10.1111/j.1469-0691.2010.03189.x

Schloss PD, Westcott SL, Ryabin T, Hall JR, Hartmann M, Hollister EB, Lesniewski RA, Oakley BB, Parks DH, Robinson CJ, Sahl JW, Stres B, Thallinger GG, Van Horn DJ, Weber CF (2009) Introducing mothur: Open-Source, Platform-Independent, Community-Supported Software for Describing and Comparing Microbial Communities. Appl Environ Microbiol 75:7537-7541. doi:10.1128/AEM.01541-09

Spangler R, Goddard NL, Thaler DS (2009) Optimizing Taq Polymerase Concentration for Improved Signal-to-Noise in the Broad Range Detection of Low Abundance Bacteria. PLoS One 4:e7010. doi:10.1371/journal.pone.0007010 
Ulrich M, Beer I, Braitmaier P, Dierkes M, Kummer F, Krismer B, Schumacher U, Grapler-Mainka U, Riethmuller J, Jensen PO, Bjarnsholt T, Hoiby N, Bellon G, Doring G (2010) Relative contribution of Prevotella intermedia and Pseudomonas aeruginosa to lung pathology in airways of patients with cystic fibrosis. Thorax 65:978-984. doi:10.1136/thx.2010.137745

van der Gast CJ, Cuthbertson L, Rogers GB, Pope C, Marsh RL, Redding GJ, Bruce KD, Chang AB, Hoffman LR (2014) Three clinically distinct chronic pediatric airway infections share a common core microbiota. Ann Am Thorac Soc 11:1039-1048. doi:10.1513/AnnalsATS.201312-456OC

Weinstein MP, Mirrett S, Van Pelt L, McKinnon M, Zimmer BL, Kloos W, Reller LB (1998) Clinical Importance of Identifying Coagulase-Negative Staphylococci Isolated from Blood Cultures:

Evaluation of MicroScan Rapid and Dried Overnight Gram-Positive Panels versus a Conventional Reference Method. J Clin Microbiol 36:2089-2092.

Winstanley C, O'Brien S, Brockhurst MA (2016) Pseudomonas aeruginosa Evolutionary Adaptation and Diversification in Cystic Fibrosis Chronic Lung Infections. Trends Microbiol 24:327-337. doi:10.1016/j.tim.2016.01.008

Yuan S, Cohen DB, Ravel J, Abdo Z, Forney LJ (2012) Evaluation of methods for the extraction and purification of DNA from the human microbiome. PLoS One 7:e33865. doi:10.1371/journal.pone.0033865

Zemanick ET, Harris JK, Wagner BD, Robertson CE, Sagel SD, Stevens MJ, Accurso FJ, Laguna TA (2013) Inflammation and airway microbiota during cystic fibrosis pulmonary exacerbations. PLoS One 8:e62917. doi:10.1371/journal.pone.0062917

Zemanick ET, Sagel SD, Harris JK (2011) The airway microbiome in cystic fibrosis and implications for treatment. Curr Opin Pediatr 23:319-324. doi:10.1097/MOP.0b013e32834604f2

Zemanick ET, Wagner BD, Harris JK, Wagener JS, Accurso FJ, Sagel SD (2010) Pulmonary exacerbations in cystic fibrosis with negative bacterial cultures. Pediatr Pulmonol 45:569-577. doi:10.1002/ppul.21221

Zhao J, Schloss PD, Kalikin LM, Carmody LA, Foster BK, Petrosino JF, Cavalcoli JD, VanDevanter DR, Murray S, Li JZ, Young VB, LiPuma JJ (2012) Decade-long bacterial community dynamics in cystic fibrosis airways. Proc Natl Acad Sci U S A 109:5809-5814. doi:10.1073/pnas.1120577109 
Table 1: Top 11 bacterial taxa in samples before and after antibiotic therapy

\begin{tabular}{|c|c|c|c|c|c|c|}
\hline \multirow[b]{2}{*}{ Bacterial species $^{\text {a }}$} & \multicolumn{3}{|c|}{ Samples before antibiotic treatment } & \multicolumn{3}{|c|}{ Samples after antibiotic treatment } \\
\hline & $\begin{array}{l}\text { The average } \\
\text { relative } \\
\text { abundance (\%) }\end{array}$ & $\begin{array}{l}\text { The number of } \\
\text { occurrences } \\
(\mathrm{N}, \%)^{\mathrm{d}}\end{array}$ & $\begin{array}{c}\text { The number of } \\
\text { samples where species } \\
\text { was dominant }(\%)^{\mathrm{e}}\end{array}$ & $\begin{array}{l}\text { The average } \\
\text { relative } \\
\text { abundance }(\%)\end{array}$ & $\begin{array}{l}\text { The number of } \\
\text { occurrences } \\
(\mathrm{N}, \%)^{\mathrm{d}}\end{array}$ & $\begin{array}{l}\text { The number of samples } \\
\text { where species was } \\
\text { dominant }(\mathrm{N}, \%)^{\mathrm{e}}\end{array}$ \\
\hline $\begin{array}{l}\text { Staphylococcus spp. }(\text { S. aureus, } S \text {. } \\
\text { epidermidis, S. hominis) }\end{array}$ & 30 & $10(63)$ & $\begin{array}{l}5(31) \text {, all of them } \\
\text { being } S . \text { aureus }\end{array}$ & 21 & $8(50)$ & $\begin{array}{c}4 \text { (25), of these: } \\
2 \text { S. aureus } \\
2 \text { S. epidermidis or } \\
\text { hominis }\end{array}$ \\
\hline Pseudomonas aeruginosa & 15 & $8(50)$ & $3(19)$ & 18 & $7(44)$ & $3(19)$ \\
\hline $\begin{array}{l}\text { Streptococcus mitis group (S. oralis, } S . \\
\text { dentisani, } S . \text { mitis, } \text { S. infantis, } S . \\
\text { tigurinus) }\end{array}$ & 9.5 & $12(75)$ & $2(6)$ & 6.9 & $9(56)$ & 0 \\
\hline Veillonella dispar & 8.0 & $12(75)$ & $1(6)$ & 5.7 & $6(38)$ & 0 \\
\hline Rothia mucilaginosa & 4.5 & $8(50)$ & 0 & 6.6 & $9(56)$ & 0 \\
\hline Prevotella melaninogenica & 4.3 & $10(63)$ & 0 & 2.9 & $6(38)$ & 0 \\
\hline Stenotrophomonas maltophilia & 0.08 & 0 & 0 & 6.6 & $2(13)$ & $1(6)$ \\
\hline $\begin{array}{l}\text { Granulicatella spp. (G. adiacens, } G . \\
\text { balaenopterae) }\end{array}$ & 1.1 & $5(31)$ & 0 & 5.2 & $6(38)$ & $1(6)$ \\
\hline $\begin{array}{l}\text { Streptococcus salivarius spp. (S. } \\
\text { thermophilus, S. salivarius) }\end{array}$ & 3.7 & $8(50)$ & 0 & 1.7 & $4(25)$ & 0 \\
\hline $\begin{array}{l}\text { Haemophilus spp. (H. influenzae, } H \text {. } \\
\text { haemolyticus) }^{\mathrm{c}}\end{array}$ & 5.09 & $2(13)$ & $1(6)$ & 0.19 & $1(6)$ & 0 \\
\hline Achromobacter xylosoxidans & 3.8 & $1(6)$ & $1(6)$ & 0.06 & 0 & 0 \\
\hline $\begin{array}{l}\text { Other species with average relative } \\
\text { abundance above } 1 \%-4.9 \%\end{array}$ & $\begin{array}{l}\text { Actinomyces o } \\
\text { paracasei, L. c }\end{array}$ & $\begin{array}{l}\text { ticus, Escheri } \\
\text { Parvimonas } m\end{array}$ & $\begin{array}{l}\text { coli, Prevotella sp. or } \\
\text { Catonella morbi ATC }\end{array}$ & $\begin{array}{l}\text { axon g70, Sca } \\
\text { 51271, Prevote }\end{array}$ & $\begin{array}{l}\text { a inopinata } \mathrm{f} 03 \\
\text { anceiensis, } F u \text { s }\end{array}$ & $\begin{array}{l}\text { actobacillus spp. ( } L \text {. } \\
\text { cterium necrophorum }\end{array}$ \\
\hline
\end{tabular}


Taxa are ordered according to their overall average relative abundance. Taxa were chosen based on their presence as a dominant pathogen or based on their average relative abundance higher than 5\%. Further taxa with an average relative abundance of $1 \%$ to $4.9 \%$ are noted in the last line of the table.

(a) Several taxa were identifiable only as a group of species because of the limited discriminating ability of the variable region 4 of the $16 \mathrm{~S}$ rRNA gene. $S$. aureus and $H$. influenzae were further distinguished from the other species within their OTU groups by specific PCR.

(b) This OTU group includes the three listed species. S. aureus was further identified in samples by specific real-time PCR targeting the nuc gene.

(c) Identified as $H$. influenzae by specific PCR.

(d) Species present in the sample by at least $1 \%$ of relative abundance.

(e) Dominance is defined as being at least $2 \mathrm{x}$ more abundant than the second most abundant species (Carmody et al. 2013; Coburn et al. 2015) 
Figure Legends and Footnotes

Figure 1 A - D: The effect of antibiotic treatment on the composition of the lung bacteriome.

(A) Relative change of taxon within the $16 \mathrm{~S}$ profile

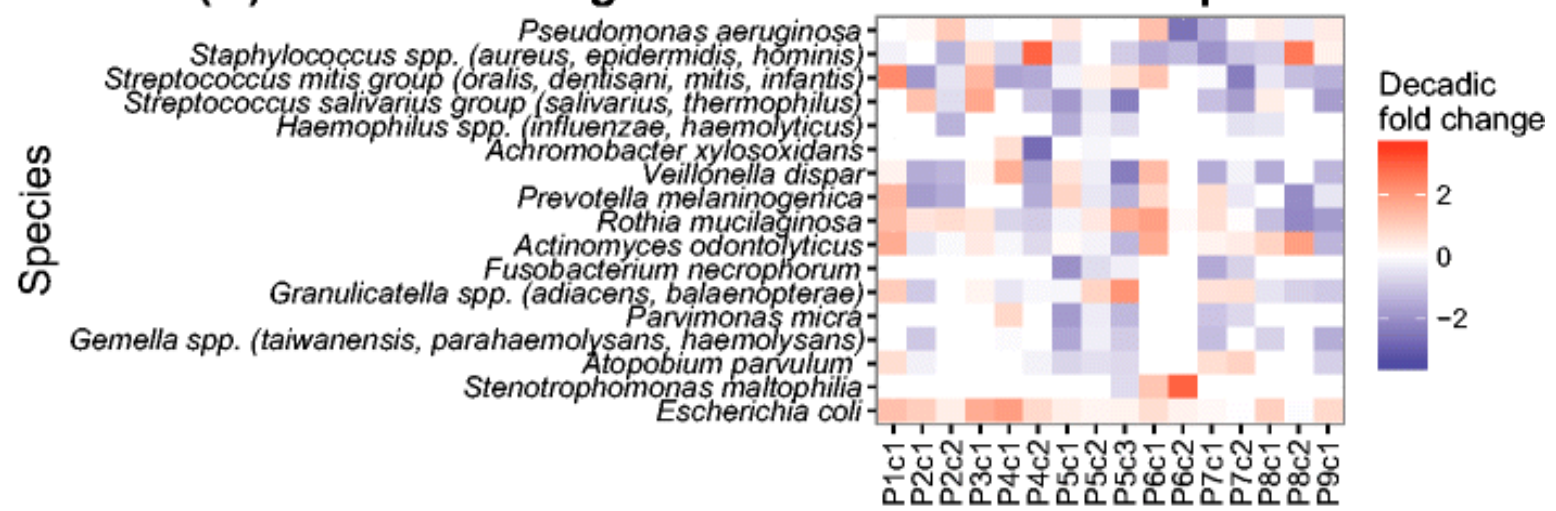

(B) Change in the true (absolute) quantity of taxon

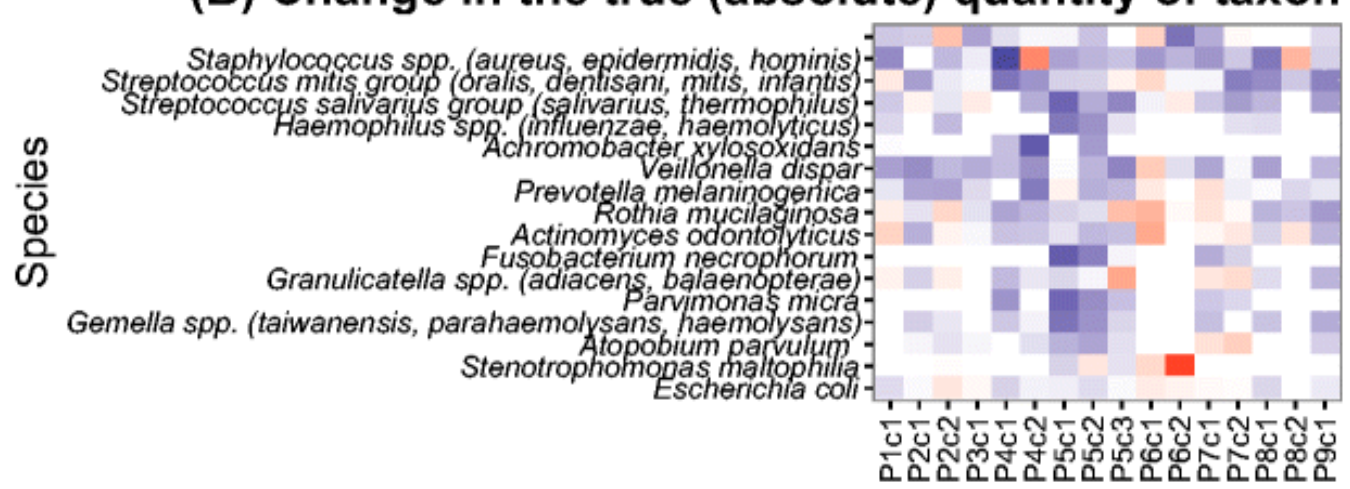

Decadic

fold change

(C) Total $16 \mathrm{~S}$ quantity by real-time PCR (all bacteria)

$\Xi$
$\Xi$
$\frac{1}{0}$
0
$\frac{0}{0}$
0
0

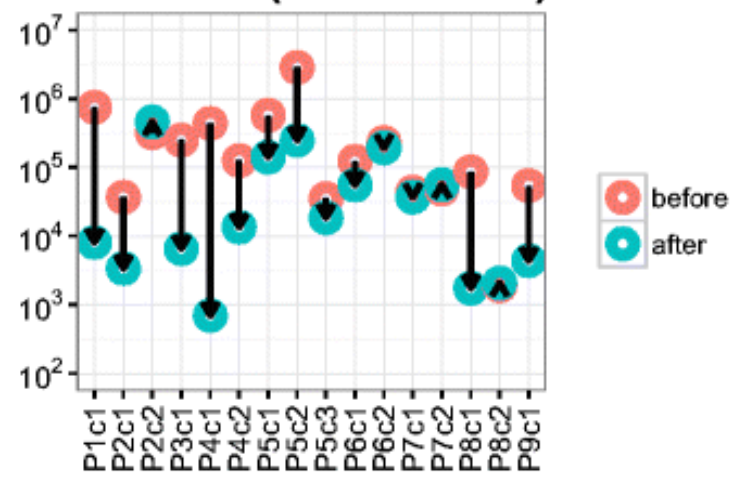

(D) Change in the total $16 \mathrm{~S}$ quantity (all bacteria)

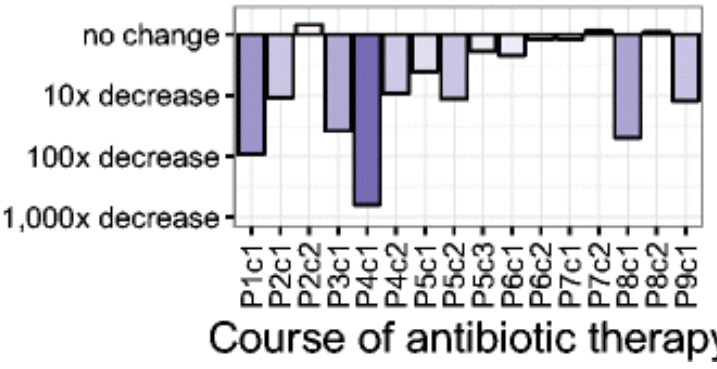

Decadic

fold change

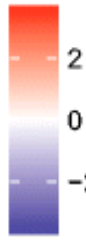

Course of antibiotic therapy 
A sample after a course of antibiotic therapy was compared to its paired sample before therapy. Changes in the sputum bacteriome were assessed by three methods.

Panel (A) - the relative 16S rDNA profiles are used for calculations of the fold-changes, disregarding the overall quantity of bacteria in the sputum sample.

Panel (B) - the fold-changes are calculated from absolute quantities of each taxa, which were derived from the proportion of the taxon within the $16 \mathrm{~S}$ rDNA profile multiplied by the absolute concentration of all bacteria in $\mu \mathrm{L}$ of sputum, as determined using real-time PCR.

Panel (C) - the total bacterial 16S rDNA concentration, assessed using real-time PCR with generic primers in pre-antibiotic sample (red circle) and its corresponding post-antibiotic sample (blue circle). The arrow shows the direction and magnitude of response.

Panel (D) - fold-change in the total bacterial concentration between the paired sputum samples taken before and after the antibiotic therapy. Identical data as in Panel C, presented in relative scale.

Panels A and B show 16 taxa with the highest relative abundance in the overall sputum bacteriome; the last, E. coli, is a product of bacterial contamination of the polymerase utilized for $16 \mathrm{~S}$ rDNA amplification (Spangler et al. 2009). The colour codes show the decadic logarithm of the relative change between the paired samples before and after the antibiotic treatment (blue for a decrease with treatment, red for an increase with treatment, white for no appreciable difference). Rows - individual bacterial taxa, ordered by the average relative share in sputum. Columns - individual episodes $=$ courses of antibiotic therapy, coded by numeric identification of the patient, and the sequential identification of the course. 
Figure 2: Changes in absolute and relative quantity of two most abundant pathogens

(A)

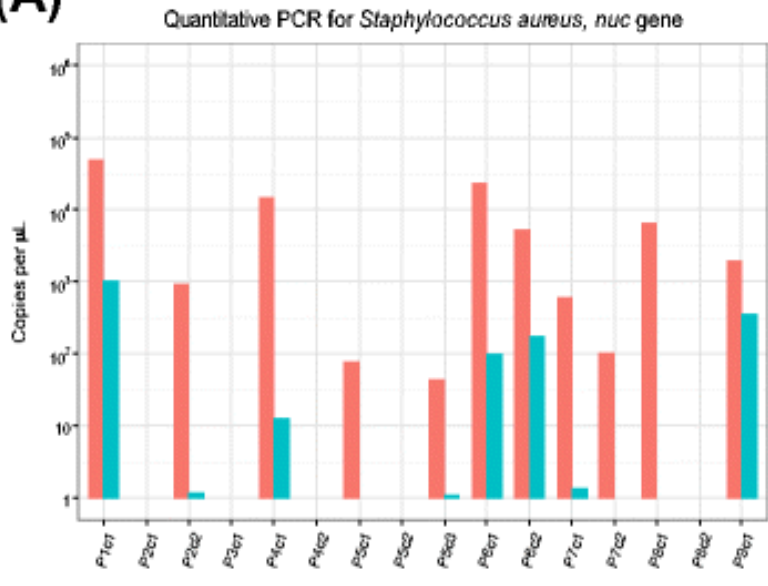

Proportion of Staphylococcus aureus / epidermidis / hominis:
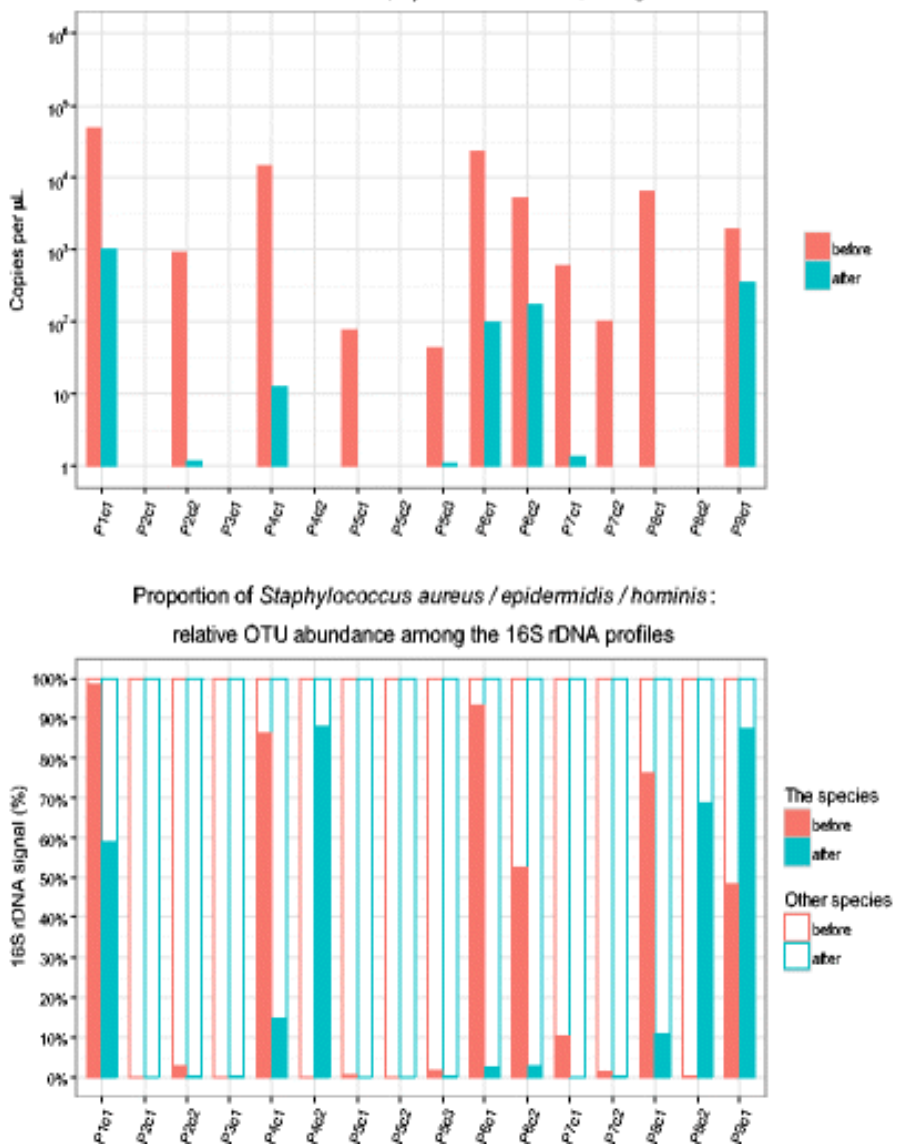

(B)
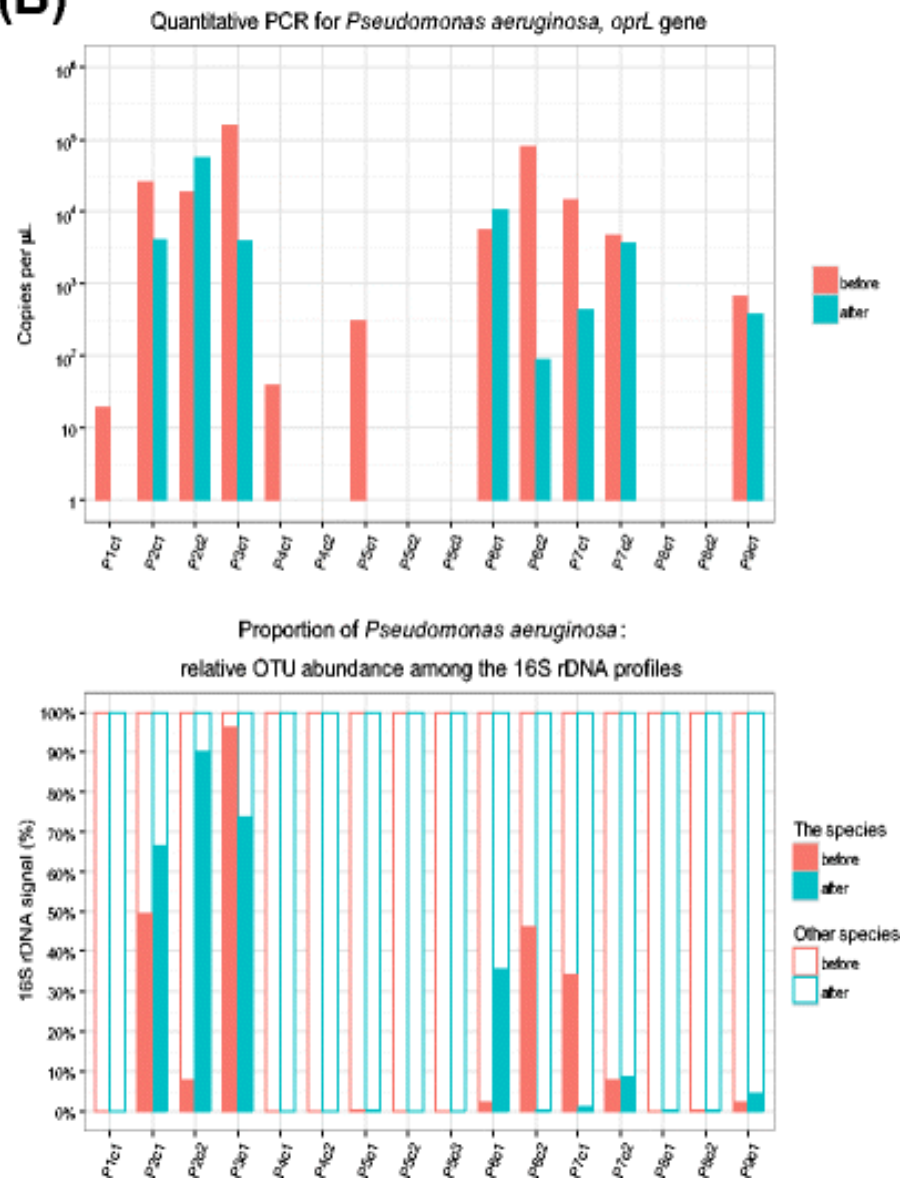

Upper graphs summarize the difference in absolute quantity (gene copies per $\mu \mathrm{L}$ ) obtained by a speciesspecific PCR. Lower graphs show the relative quantities (\%) from 16S rDNA sequencing. The pre- versus post-antibiotic samples are coded by colours of the bar .

(A) S. aureus and its changes over the courses of antibiotic treatment. While the specific detection shows a good response to antibiotic treatment, the $16 \mathrm{~S}$ rDNA sequencing (lower panel) in antibiotic courses P4c2 and P8c2 documents an increase in the proportion of reads: the V4 region of the rDNA gene does not allow distinguishing S. aureus from S. epidermidis and S. hominis, this signal therefore comes from either of the latter two species. 
(B) P. aeruginosa and its changes over the courses of antibiotic treatment. Species-specific PCR had a lower detection threshold than 16S rDNA sequencing. 
Figure 3: Changes in relative abundance of the top 11 taxa assessed by NGS

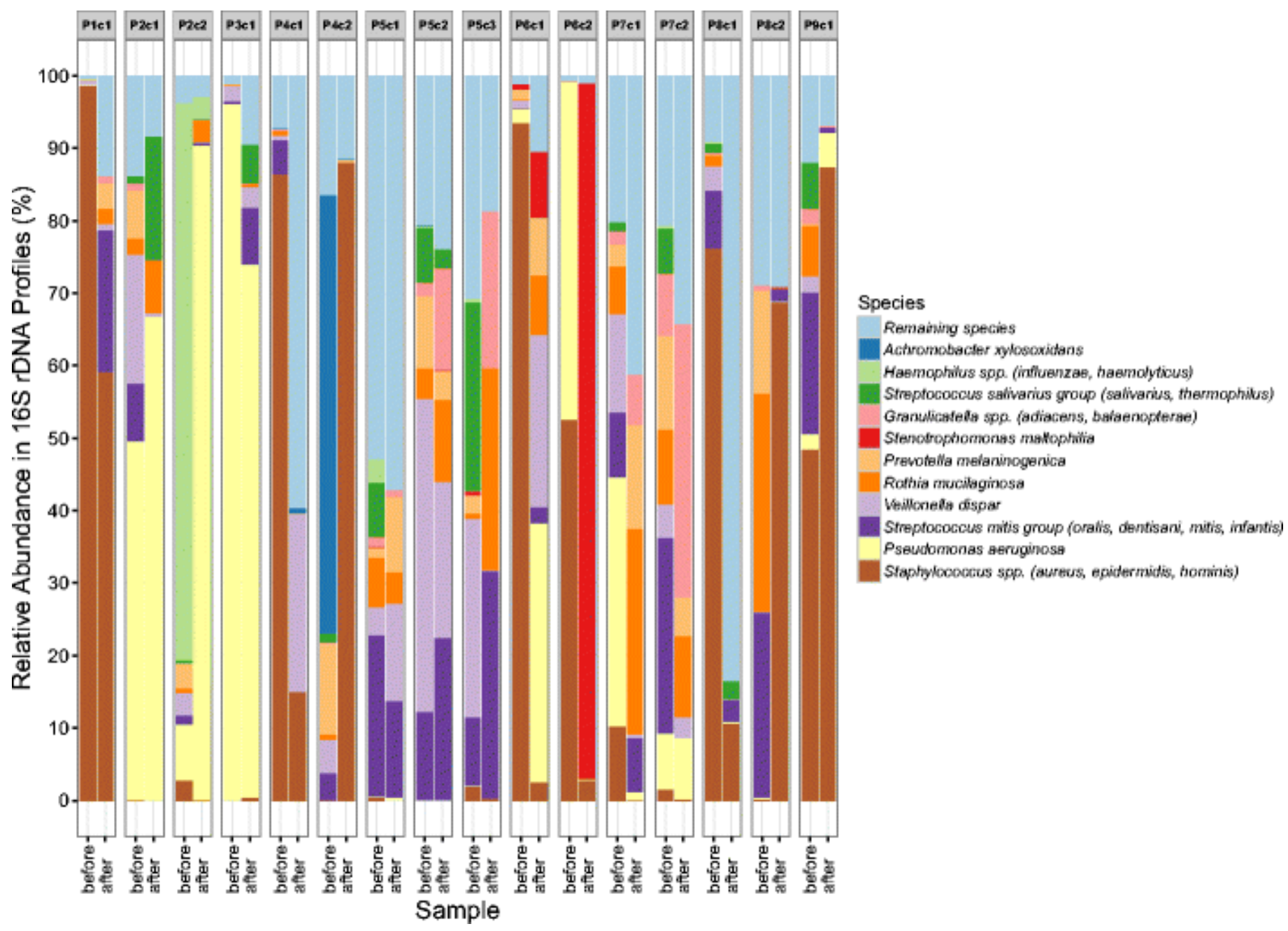

Each pair of bars represents one course of antibiotic therapy; the first bar represents a sample taken at the beginning of antibiotic therapy (referred to as "before") and the second is taken at the end of the therapy (referred to as "after"). Patient and the course of antibiotic treatment are identified at the top of the bar.

Each colour represents the fraction of one of the top11 OTUs. These 11 were selected because of their presence as a dominant pathogen in any of the samples or if their average relative abundance exceeded $5 \%$. Several OTUs were identified only as a group of taxa that could not be distinguished by the V4 region of the $16 \mathrm{~S}$ rRNA gene - therefore potential species of this OTU are listed.

The sum of remaining OTUs is shown in light blue, and they fill each bar up to $100 \%$. 